\title{
Dependence of ice-core relative trace-element concentration on acidification
}

\author{
Bess G. KOFFMAN, ${ }^{1,2 *}$ Michael J. HANDLEY, ${ }^{1}$ Erich C. OSTERBERG, ${ }^{3}$ Mark L. WELLS, ${ }^{4}$ \\ Karl J. KREUTZ ${ }^{1,2}$ \\ ${ }^{1}$ School of Earth and Climate Sciences, University of Maine, Orono, ME, USA \\ E-mail: bess.koffman@maine.edu \\ ${ }^{2}$ Climate Change Institute, University of Maine, Orono, ME, USA \\ ${ }^{3}$ Department of Earth Sciences, Dartmouth College, Hanover, NH, USA \\ ${ }^{4}$ School of Marine Sciences, University of Maine, Orono, ME, USA
}

\begin{abstract}
To assess the role of methodological differences on measured trace-element concentrations in ice cores, we developed an experiment to test the effects of acidification strength and time on dust dissolution using snow samples collected in West Antarctica and Alaska. We leached Antarctic samples for 3 months at room temperature using nitric acid at concentrations of $0.1,1.0$ and $10.0 \%(\mathrm{v} / \mathrm{v})$. At selected intervals (20 min, 24 hours, 5 days, 14 days, 28 days, 56 days, 91 days) we analyzed 23 trace elements using inductively coupled plasma mass spectrometry. Concentrations of lithogenic elements scaled with acid strength and increased by $100-1380 \%$ in 3 months. Incongruent elemental dissolution caused significant variability in calculated crustal enrichment factors through time (factor of $1.3(\mathbf{P b})$ to 8.0 (Cs)). Using snow samples collected in Alaska and acidified at $1 \%(\mathrm{v} / \mathrm{v})$ for 383 days, we found that the increase in lithogenic element concentration with time depends strongly on initial concentration, and varies by element (e.g. Fe linear regression slope $=1.66 ; r=0.98$ ). Our results demonstrate that relative trace-element concentrations measured in ice cores depend on the acidification method used.
\end{abstract}

KEYWORDS: ice and climate, snow and ice chemistry

\section{INTRODUCTION}

Ice-core records provide evidence of past changes in atmospheric chemistry and transport linked both to globaland regional-scale climate variability (e.g. Mayewski and others, 1994; Kreutz and Sholkovitz, 2000; Fischer and others, 2007) and to anthropogenic pollution and land-use changes (McConnell and others, 2002, 2007; Vallelonga and others, 2002; Osterberg and others, 2008) on a range of timescales. Impurities in glacial ice come from the deposition of particulate and soluble aerosols on the snow surface, which in turn are sourced from mineral dust, volcanic eruptions, sea spray, biological emissions and anthropogenic pollution. The physical and chemical properties of these impurities allow detection using a range of analytical tools. The analysis of trace elements using inductively coupled plasma mass spectrometry (ICP-MS) has become widely used for reconstructing past changes in the atmospheric burden of pollutants such as $\mathrm{Pb}$ (e.g. McConnell and others, 2002; Vallelonga and others, 2002; Hong and others, 2004; Osterberg and others, 2008; Gross and others, 2012) and the deposition of important bioactive metals such as Fe (e.g. Edwards and others, 2006; Gaspari and others, 2006). In addition, changes in the composition of dust, signaling changes in its source, have been inferred using ICP-MS measurements (Kreutz and Sholkovitz, 2000; Gabrielli and others, 2010).

Ice-core samples are prepared for ICP-MS analysis by melting and acidification, and are then either injected directly into the mass spectrometer (McConnell and others,

*Present address: Lamont-Doherty Earth Observatory, Columbia University, Palisades, NY, USA.
2002) or analyzed in individual vials, in both cases usually without filtration (Knüsel and others, 2003; Osterberg and others, 2006). Acidification of ice-core samples is necessary in order to maintain sample stability during analysis. Methods for acidifying samples vary in terms of the mineral acid used, acid strength and acid contact time. Samples are commonly acidified to $1 \%(\mathrm{v} / \mathrm{v})$ nitric acid, whether as discrete samples (e.g. Osterberg and others, 2006) or as a liquid stream for continuous injection (e.g. McConnell and others, 2002), though a weaker $0.5 \%$ nitric acid addition has also been used (e.g. Krachler and others, 2005, 2008; Grotti and others, 2011). Hydrochloric acid has been used to acidify samples, but is less common (Edwards and others, 2006). Perhaps the greatest source of methodological difference is the acid contact time. Continuous injection ICP-MS allows for an acid contact time of seconds to minutes, while discrete samples may be acidified for any length of time. Although few ice-core studies have stated explicitly how long samples were acidified prior to ICP-MS analysis (table 1 of Rhodes and others, 2011), it is apparent that 24 hours is a common length of acidification (Krachler and others, 2005; Osterberg and others, 2006).

A study using synthetic dust samples has suggested that acidification time has a significant impact on measured trace-element concentrations (Rhodes and others, 2011), but no systematic test has been conducted on actual snow or ice-core samples. Considering the variety of techniques commonly used in ice-core trace-element analysis, we conducted a 3 month experiment to evaluate trace-element dissolution from atmospheric dust in West Antarctic surface snow samples at nitric acid concentrations of $0.1,1.0$ and $10.0 \%(\mathrm{v} / \mathrm{v})$. The goal was to evaluate the effects of acid strength and time on dust dissolution and the impact that 
Table 1. ICP-SFMS instrument conditions and measurement parameters

\section{Forward power \\ Cool gas \\ Auxiliary gas \\ Sample gas \\ Additional gas \\ Sample uptake}

Number of scans

$$
\begin{gathered}
1280 \mathrm{~W} \\
16 \mathrm{~L} \mathrm{~min}^{-1} \\
0.95 \mathrm{~L} \mathrm{~min}^{-1} \\
\sim 0.8 \mathrm{~L} \mathrm{~min}^{-1} \\
\sim 0.2 \mathrm{~L} \mathrm{~min}^{-1} \\
100 \mu \mathrm{L} \mathrm{min}^{-1}
\end{gathered}
$$

15 differential dissolution rates could have on calculated crustal enrichment factors. In addition, we used a time series of snow-pit samples collected from Denali National Park, Alaska, USA, and measured twice (383 days apart, at $1 \%(\mathrm{v} / \mathrm{v})$ nitric acid) to investigate the concentration dependence of measured increases in trace-element concentrations through time. Our study expands the work of Rhodes and others (2011) by testing the effects of both acid strength and time on real environmental samples from Alaska and Antarctica, two important ice-core drilling locations. Dust particles deposited in the snowpack at both sites are likely to have experienced significant weathering relative to their source rock, particularly during atmospheric transport (Cwiertny and others, 2008). Our results are directly relevant to ice-core studies of trace-element deposition. In addition, we evaluate the concentration dependence of relative changes in four trace-element concentrations (Al, Ca, Fe and S) measured over 1 year of acidification. Our results imply that ice-core time-series records developed after relatively short acidification periods likely underestimate both the magnitude and the variability of trace-element concentrations, potentially leading to bias in paleoclimate calibration work, which in turn could impact interpretations of past climate variability based on trace-element proxies.

\section{METHODS}

\section{Sample collection: WAIS Divide, Antarctica}

Snow samples were collected from a $2.6 \mathrm{~m}$ snow pit dug in 2008 at the West Antarctic ice sheet (WAIS) Divide ice-core site $\left(79.468^{\circ} \mathrm{S}, 112.086^{\circ} \mathrm{W} ; 1766 \mathrm{~m}\right.$ a.s.I.) within the cleanair sector of camp. Once the snow pit was excavated, one wall was cut back an additional $\sim 20 \mathrm{~cm}$ using a plastic shovel cleaned with Citranox detergent and Millipore Milli$\mathrm{Q}$ deionized water. The wall was subsequently scraped back an additional $\sim 4 \mathrm{~cm}$ using plastic scrapers that had been decontaminated using nitric acid and Milli-Q water. Sampling personnel wore Tyvek clean suits and double pairs of gloves; gloves were replaced whenever they became torn. Snow samples were collected using a specially built pure $\mathrm{Ti}$ sampling tool, which had been washed with Citranox detergent and Milli-Q water. Each acid-washed sample bottle was double-bagged for storage and shipment using plastic Ziploc bags to reduce contact with the environment. Samples were shipped frozen to the University of Maine and stored in a freezer until melting and analysis.

\section{Experimental set-up}

We combined Antarctic snow from several sample bottles and melted it in an acid-cleaned, capped Teflon ${ }^{\mathbb{R}}$ perfluoroalkoxy (PFA)-coated bottle using a warm water bath. Once the snow was fully melted, we homogenized it by shaking and inverting the bottle, then poured the water into three additional PFA bottles $(\sim 110 \mathrm{~mL}$ each). We then added Optima grade nitric acid (Fisher Scientific) to each bottle, resulting in volumetric concentrations of $0.1,1.0$ and $10 \%$ acid, respectively. We evaluated possible sorption of metals to the walls of the bottle used for melting the snow by swishing the bottle with a $10 \%$ nitric acid solution. Metal sorption was negligible $(\sim 0.5 \%$ of initial measured concentrations).

We analyzed samples after $20 \mathrm{~min}, 24$ hours, 5 days, 14 days, 28 days, 56 days and 91 days. At each analysis time, we poured five replicates from each bottle (to avoid potential contamination from a pipette) into acid-cleaned $4 \mathrm{~mL}$ polypropylene (PP) vials for analysis. Samples were either analyzed immediately or frozen until later analysis. We analyzed samples using a Thermo Finnigan Element II inductively coupled plasma sector-field mass spectrometer (ICP-SFMS) with an ESI Apex sample introduction system and a PFA-ST nebulizer. Instrumental settings for the ICP-SFMS are given in Table 1. Procedural blanks (Milli-Q water) were treated identically and analyzed in parallel (e.g. 0.1, 1.0 and $10.0 \%(\mathrm{v} / \mathrm{v})$ Optima grade nitric acid concentrations). All bottles were shaken periodically (about once a week) and prior to subsampling, and were kept in the dark at room temperature. All sample handling was conducted in a class 1000 clean room under a laminar flow High Efficiency Particle Air (HEPA) bench. Unfortunately, because we poured off replicates (rather than using a pipette for volumetric accuracy), we ran out of sample earlier than planned, and were not able to quantify recovery rates using hydrofluoric acid (HF) digestion.

All five replicates were included in the calculations of mean concentration and standard deviation; the error bars shown are one standard deviation (1SD) of the mean concentration for each analysis time. Because melted snow and ice samples include both dissolved and suspended impurities, they are inherently heterogeneous; therefore, the standard deviation of each set of replicates likely represents real sample variability. We subtracted the average of five blank replicate measurements (for each acid treatment, at each analysis time) from each mean sample concentration, to correct for potential analytical inconsistencies. Blank concentrations remained well below the sample concentrations throughout the experiment (over an order of magnitude for most elements; Table 2). Data from this study will be made publicly available through the US National Snow and Ice Data Center (NSIDC).

\section{Sample collection and treatment: Denali National Park, Alaska}

Snow samples were collected from a $4 \mathrm{~m}$ pit dug at Kahiltna Pass, Denali National Park, in $2008\left(63.076^{\circ} \mathrm{N}\right.$, $151.174^{\circ} \mathrm{W}$; 2957 ma.s.l.; Campbell and others, 2012). Samples were collected at $5 \mathrm{~cm}$ resolution using trace metal clean techniques (as described above), and were stored in acid-washed bottles. Snow samples were shipped frozen, then melted and acidified to $1 \%(\mathrm{v} / \mathrm{v})$ with Optima grade nitric acid under a HEPA bench. Samples were analyzed using ICP-SFMS at two time intervals spaced 383 days apart, and were stored at room temperature in the intervening time. All sample handling was conducted in a class 1000 clean laboratory. 
Table 2. Instrumental detection limit (IDL) and mean of 35 blank measurements with 1 SD error. Blanks acidified to $0.1,1.0$ and $10.0 \%(\mathrm{v} / \mathrm{v})$ nitric acid, respectively; all values reported in $\mathrm{ng} \mathrm{L}^{-1}$. The number of reported decimal places reflects the analytical precision associated with measurement of each element

\begin{tabular}{|c|c|c|c|c|c|}
\hline Analyte* & $\begin{array}{c}\text { Instrumental detection } \\
\text { limit }^{\dagger}\end{array}$ & $0.1 \%$ acid blank & $1.0 \%$ acid blank & $10.0 \%$ acid blank & Factor of difference \\
\hline
\end{tabular}

\begin{tabular}{|c|c|c|c|c|c|}
\hline${ }^{27} \mathrm{Al}(\mathrm{MR})$ & 6.78 & $66.9 \pm 39.4$ & $55.0 \pm 32.8$ & $73.1 \pm 46.5$ & 25 \\
\hline${ }^{75} \mathrm{As}(\mathrm{MR})$ & 0.09 & $0.16 \pm 0.09$ & $0.17 \pm 0.12$ & $0.25 \pm 0.23$ & 15 \\
\hline${ }^{138} \mathrm{Ba}(\mathrm{LR})$ & 0.161 & $0.666 \pm 0.321$ & $0.847 \pm 0.505$ & $0.932 \pm 0.618$ & 27 \\
\hline${ }^{44} \mathrm{Ca}(\mathrm{MR})$ & 101.2 & $425.1 \pm 207.6$ & $378.9 \pm 181.9$ & $513.3 \pm 298.7$ & 16 \\
\hline${ }^{111} \mathrm{Cd}(\mathrm{LR})$ & 0.032 & $0.125 \pm 0.104$ & $0.073 \pm 0.052$ & $0.093 \pm 0.048$ & 18 \\
\hline${ }^{140} \mathrm{Ce}(\mathrm{LR})$ & 0.007 & $0.204 \pm 0.543$ & $0.098 \pm 0.069$ & $0.076 \pm 0.034$ & 19 \\
\hline${ }^{59} \mathrm{Co}(\mathrm{MR})$ & 0.074 & $0.096 \pm 0.058$ & $0.094 \pm 0.046$ & $0.092 \pm 0.049$ & 13 \\
\hline${ }^{52} \mathrm{Cr}(\mathrm{MR})$ & 0.122 & $0.414 \pm 0.221$ & $0.465 \pm 0.238$ & $0.516 \pm 0.223$ & 103 \\
\hline${ }^{133} \mathrm{Cs}(\mathrm{MR})$ & 0.006 & $0.043 \pm 0.029$ & $0.047 \pm 0.030$ & $0.053 \pm 0.033$ & 8 \\
\hline${ }^{63} \mathrm{Cu}(\mathrm{MR})$ & 2.391 & $2.926 \pm 2.662$ & $3.284 \pm 2.721$ & $3.187 \pm 2.478$ & 35 \\
\hline${ }^{56} \mathrm{Fe}(\mathrm{MR})$ & 9.5 & $19.5 \pm 13.1$ & $24.1 \pm 22.8$ & $21.4 \pm 10.2$ & 64 \\
\hline${ }^{39} \mathrm{~K}(\mathrm{HR})$ & 140.9 & $<\mathrm{IDL}$ & $<\mathrm{IDL}$ & $<\mathrm{IDL}$ & $>8$ \\
\hline${ }^{139} \mathrm{La}(\mathrm{LR})$ & 0.024 & $0.049 \pm 0.028$ & $0.063 \pm 0.033$ & $0.055 \pm 0.028$ & 16 \\
\hline${ }^{24} \mathrm{Mg}(\mathrm{MR})$ & 19.6 & $86.3 \pm 82.6$ & $73.2 \pm 51.9$ & $102.4 \pm 164.3$ & 35 \\
\hline${ }^{55} \mathrm{Mn}(\mathrm{MR})$ & 0.453 & $0.463 \pm 0.274$ & $0.534 \pm 0.255$ & $0.661 \pm 0.285$ & 48 \\
\hline${ }^{208} \mathrm{~Pb}(\mathrm{LR})$ & 0.065 & $0.436 \pm 0.364$ & $0.459 \pm 0.343$ & $0.499 \pm 0.324$ & 29 \\
\hline${ }^{141} \operatorname{Pr}(\mathrm{LR})$ & 0.005 & $0.017 \pm 0.016$ & $0.018 \pm 0.015$ & $0.014 \pm 0.10$ & 18 \\
\hline${ }^{32} \mathrm{~S}(\mathrm{MR})$ & 126.4 & $280.1 \pm 266.7$ & $248.2 \pm 209.4$ & $265.8 \pm 234.2$ & 26 \\
\hline${ }^{88} \mathrm{Sr}(\mathrm{LR})$ & 0.22 & $0.50 \pm 0.28$ & $0.42 \pm 0.28$ & $0.62 \pm 0.40$ & 48 \\
\hline${ }^{47} \mathrm{Ti}(\mathrm{MR})$ & 0.496 & $4.588 \pm 3.394$ & $4.980 \pm 2.577$ & $4.871 \pm 3.119$ & 31 \\
\hline${ }^{238} \mathrm{U}(\mathrm{LR})$ & 0.006 & $0.009 \pm 0.003$ & $0.008 \pm 0.004$ & $0.012 \pm 0.004$ & 12 \\
\hline${ }^{51} \mathrm{~V}(\mathrm{MR})$ & 0.093 & $0.300 \pm 0.144$ & $0.447 \pm 0.334$ & $0.382 \pm 0.265$ & 7 \\
\hline${ }^{66} \mathrm{Zn}(\mathrm{MR})$ & 6.142 & $28.941 \pm 47.436$ & $27.906 \pm 31.427$ & $19.855 \pm 15.776$ & 11 \\
\hline
\end{tabular}

*LR indicates low-resolution mode $(m / \Delta m=300)$, MR indicates medium-resolution mode $(m / \Delta m=4000)$ and HR indicates high-resolution mode $(m / \Delta m=10000)$ for the ICP-SFMS.

†Instrumental detection limit calculated as 3SD of ten water blanks.

*Factor of difference is average sample concentration divided by average blank concentration for each analysis time, averaged for the seven analysis times. The reciprocal of this number indicates the fraction of the sample concentration represented by the blank concentration.

\section{RESULTS AND DISCUSSION}

\section{Effects of acid strength and acidification time on measured concentrations}

We tested the effects of two variables, acid strength and acidification time, on the measured concentration of trace elements in West Antarctic snow samples. While both variables had a positive effect on the measured concentration, we observed that the magnitude of concentration change depended on the element analyzed (Fig. 1). In general, increases with time were greater for the $0.1 \%$ acid treatment, because the initial concentration was low compared with the 1.0 and $10.0 \%$ acid treatments. Elements that increased minimally (i.e. $<100 \%$ ) relative to the initial concentration for all acid treatments include $\mathrm{Mg}, \mathrm{S}, \mathrm{K}, \mathrm{Ca}$ and Cs. Elements that increased substantially with time $(>100 \%$ after $\leq 1$ month) for all three acid treatments include $\mathrm{Al}, \mathrm{Mn}$, $\mathrm{Fe}, \mathrm{Cu}, \mathrm{Cd}, \mathrm{La}, \mathrm{Ce}, \mathrm{Pb}$ and $\mathrm{U}$. We also observed large differences among the acid treatments, particularly early in the experiment. For example, from 20 min to 24 hours, Al increased by 7,10 and $20 \%$, respectively, for the $0.1,1.0$ and $10.0 \%$ acid treatments. From $20 \mathrm{~min}$ to 5 days, $\mathrm{Al}$ increased by 32,62 and $82 \%$, respectively, and, after 3 months, $\mathrm{Al}$ concentrations increased by 345,374 and $397 \%$ for the three treatments. Although the relative differences among acid treatments decreased with time, Al concentrations at 3 months were still significantly different among the three treatments $\left(2.1 \pm 0.18,2.5 \pm 0.11\right.$ and $3.0 \pm 0.11 \mu \mathrm{g} \mathrm{L}^{-1}$, respectively; errors given are $1 \mathrm{SD})$. Elements generally associated with soil dust (e.g. Al, Ti, V, Fe, Mn, La, Ce, Pr) were consistently leached more effectively by stronger acid; at the end of the 3 month experiment, concentrations of these elements were $>1$ SD different from each other (e.g. Fe and Mn dissolution curves in Fig. 2). In contrast, more soluble elements such as $\mathrm{K}$ and $\mathrm{Ca}$ reached equivalent concentrations among the three acid treatments after 2-4 weeks (e.g. Ca dissolution curve in Fig. 2).

Our second observation concerns the shape of the concentration profile. Figure 2 shows the four dominant patterns we observed. The Ca curve reveals that acid strength is the dominant factor affecting its measured concentration during the first 2 weeks, after which point the concentrations become statistically indistinguishable. K, Cs and As show a similar pattern (not shown). In addition, we observe that for the $1 \%$ and $10 \%$ acid treatments, the Ca concentration increases by $\sim 1 \mu \mathrm{gL}^{-1}$ from $20 \mathrm{~min}$ to 24 hours, then decreases by $\sim 1.5 \mu \mathrm{g} \mathrm{L}^{-1}$ at 5 days, after which it increases by $\sim 0.5 \mu \mathrm{g} \mathrm{L}^{-1}$ to its final value. We infer that some of the Ca precipitated and redissolved during this interval. The $\mathrm{Cd}$, Fe and Mn curves show a common feature of the concentration profiles of most elements: a change in slope that occurs after about 2 weeks to 1 month. While the $\mathrm{Cd}$ and Mn concentrations appear to be reaching a steady state, the slope of the $10 \%$ acid Fe concentration curve suggests that at 3 months, Fe is still actively leaching into solution; $\mathrm{Al}$ has a similar pattern (not shown). The concentrations of all other dustborne elements appear to have a decreasing slope from 1 to 3 months, suggesting that their concentrations are approaching a maximum acid-leachable fraction. This difference in slope between Fe and $\mathrm{Al}$ and other lithogenic elements may 


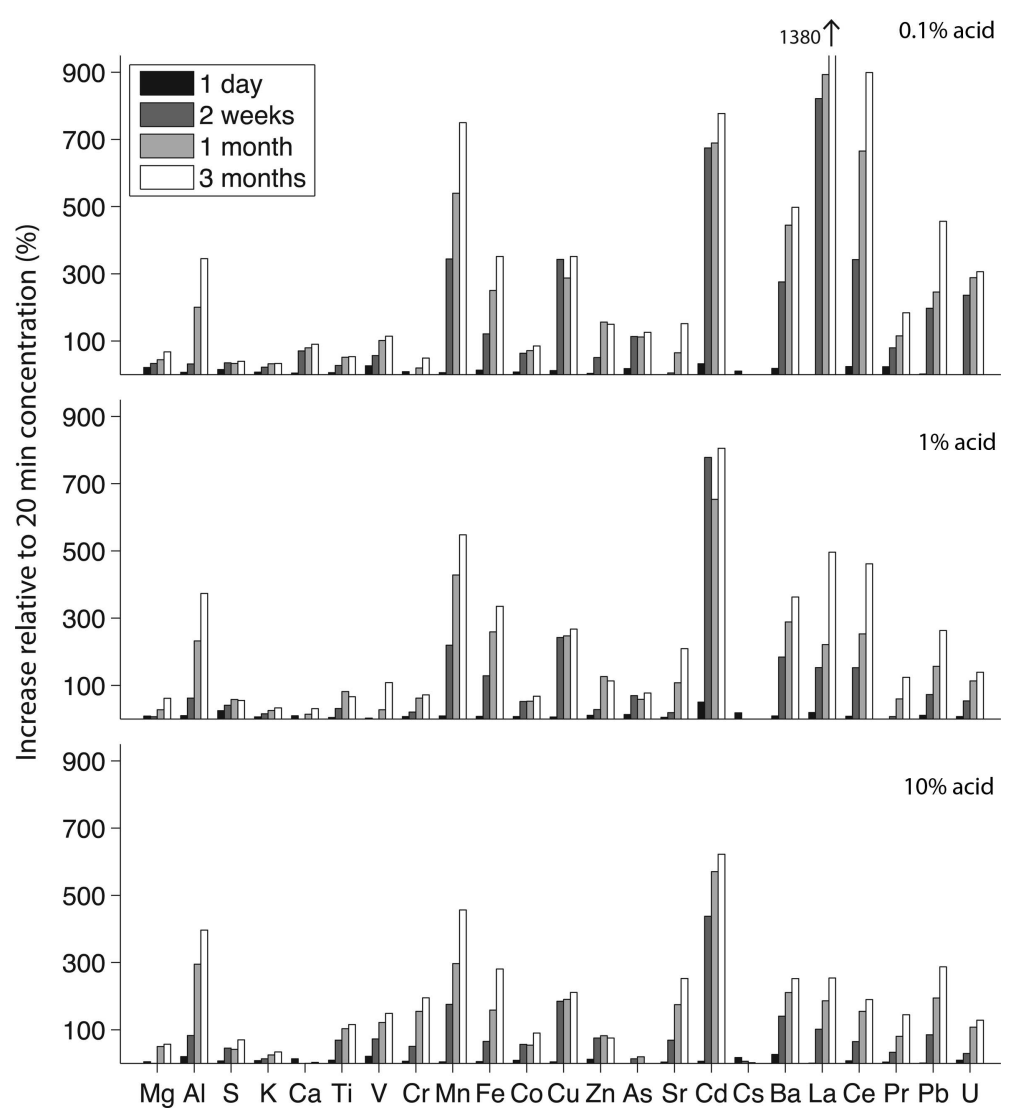

Fig. 1. Bar plot showing percent increase in elemental concentration relative to the 20 min analysis, for selected acidification times, for each acid treatment. Snow-pit samples collected in Antarctica.

be explained by results from an East Antarctic trace-element study. Grotti and others (2011) used $0.45 \mu \mathrm{m}$ filtration and two acid treatments $(0.5 \%(\mathrm{v} / \mathrm{v})$ nitric acid and an $\mathrm{HF}$ digestion) to evaluate particulate vs dissolved and acid- leachable vs total fractions of trace elements in surface snow. They found that $80-100 \%$ of Fe and Al was contained within the particulate fraction, while the particulate fraction of the lithogenic elements $\mathrm{Co}, \mathrm{Cr}, \mathrm{Mn}, \mathrm{Pb}$ and $\mathrm{V}$ ranged from
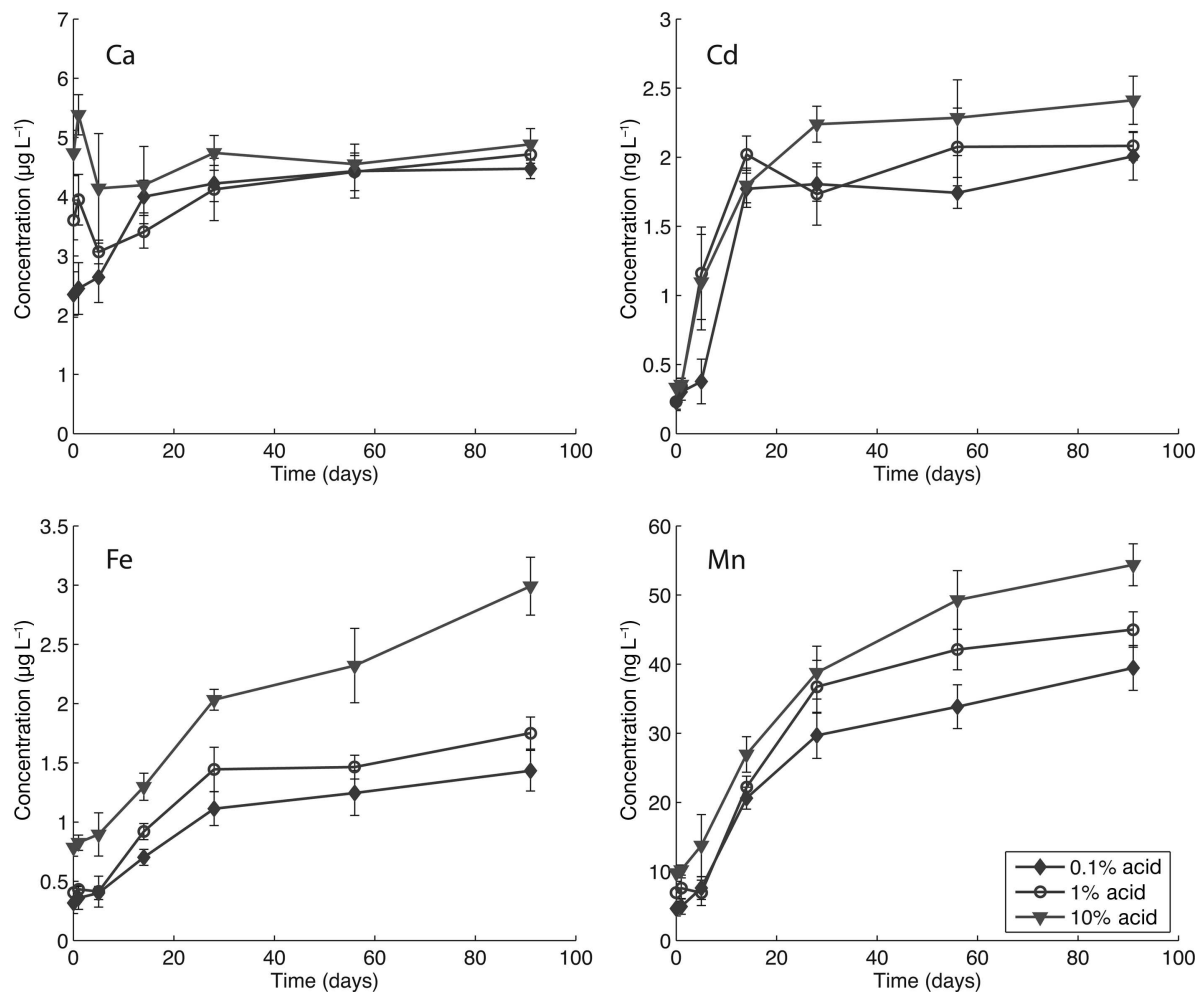

Fig. 2. Concentrations of $\mathrm{Ca}, \mathrm{Cd}$, Fe and $\mathrm{Mn}$ with acidification time for each acid treatment measured in snow-pit samples from Antarctica. 
20 to $70 \%$ (Grotti and others, 2011). Thus the prolonged increases of $\mathrm{Fe}$ and $\mathrm{Al}$ concentrations in our samples likely reflect continuing dissolution of relatively refractory aluminosilicate and oxide minerals in dust.

Our results are consistent with those from other studies. Although they used a different type of acid (hydrochloric, added to reach $\mathrm{pH}$ 1.9), Edwards and others (2006) found that Fe concentrations leaching out of dust in snow samples from Law Dome, Antarctica, increased by a factor of three within the first month of acidification, and continued to increase for up to 3 months. Rhodes and others (2011) found that elemental dissolution from four different crushed rock standards (JG-2, granite; Nod-P-1, ferromanganese nodule; BHVO-2, basalt; and $\mathrm{W}-2$, dolerite) acidified at $1 \%(\mathrm{v} / \mathrm{v})$ nitric acid was both time- and mineral-dependent. Over the course of 2 months at room temperature, $\mathrm{Al}$ and $\mathrm{Mn}$ increased by $\sim 350-5000 \%$ and $\sim 100-500 \%$, respectively, among the four rock standards (Rhodes and others, 2011). Elemental dissolution rates varied substantially: Mn concentrations in the JG-2 leachate approximately doubled in the first 3 weeks, then remained constant. In contrast, Al concentrations changed at a relatively consistent rate over the course of 12 weeks, increasing by a factor of $\sim 4$ over this time interval (Rhodes and others, 2011). In leachate from the Nod-P-1 standard, $\mathrm{Al}$ increased by a factor of $\sim 3$ in the first $\sim 12$ hours, then increased at a slowing rate until around 2 weeks, after which its concentration remained stable. Thus, trace-element dissolution depends on the mineralogy of the rock standard used, a finding that has direct implications for ice-core studies because the composition of dust deposited at ice-core sites changes as dust sources and transport change through time (e.g. Marino and others, 2004; Revel-Rolland and others, 2006; Bory and others, 2010).

The significant increases observed in trace-element concentrations as a function of acidification time have direct relevance to the different ICP-MS methodologies currently employed by the ice-core community. As stated earlier, the major difference among studies is the use of continuous vs discrete ICP-MS sample analysis, and the resulting differences in acid contact time. Although we did not analyze samples within seconds to minutes of acidification, our results show that the concentrations of most elements measured after 20 min of acidification did not represent those achieved after 3 months (Fig. 1). Knüsel and others (2003) undertook a direct comparison of conventionally cut and decontaminated ice-core samples with samples melted continuously and analyzed using a continuousinjection ICP-MS. They found that the continuous-injection method achieved similar concentrations of relatively soluble elements such as $\mathrm{Na}, \mathrm{Mg}$ and $\mathrm{Sr}$, but measured significantly lower concentrations of $\mathrm{Al}, \mathrm{V}, \mathrm{Fe}, \mathrm{As}, \mathrm{Rb}, \mathrm{Cd}, \mathrm{Sb}, \mathrm{Cs}, \mathrm{Ba}, \mathrm{La}$, $\mathrm{Ce}, \mathrm{Pr}, \mathrm{Nd}, \mathrm{Sm}, \mathrm{Pb}, \mathrm{Bi}$, Th and $U$ compared with the conventional method. They attributed the lower concentration results of these lithogenic elements to reduced acid contact time (Knüsel and others, 2003). It is clear that results obtained using these two approaches are not comparable because of the inherent differences in the duration of acidification prior to analysis.

\section{Effect of variable elemental dissolution on calculated crustal ratios and crustal enrichment factors}

Lithogenic elements such as $\mathrm{Al}, \mathrm{Ce}, \mathrm{Fe}, \mathrm{La}$ and $\mathrm{Mn}$ are commonly used as crustal dust tracers (e.g. McConnell and others, 2007). In turn, the enrichment of various trace elements (such as $\mathrm{Pb}, \mathrm{Bi}$ and $\mathrm{As}$ ) relative to their ratio to a given lithogenic element (or elements) in the upper continental crust (UCC) is used to infer the presence of non-crustal sources, or of changes in dust provenance through time (Gabrielli and others, 2005; Osterberg and others, 2008; Marteel and others, 2009; Dixon and others, 2013). The crustal enrichment factor $\mathrm{EF}_{\mathrm{C}}$ is defined as $R_{\text {sample }} / R_{\mathrm{UCC}}$, where $R$ is the ratio of the element of interest to a given reference element, such as Al. Although Reimann and De Caritat (2000) argued that enrichment factors have limited utility in environmental geochemistry, they remain a widely used tool within the ice-core community.

To explore how differential dissolution rates affect calculated crustal ratios and enrichment factors, we evaluated all trace elements in relation to $\mathrm{Al}, \mathrm{Ce}, \mathrm{Fe}, \mathrm{La}$ and $\mathrm{Mn}$. While our analysis suggests that many elements have sources other than continental dust (i.e. marine and volcanic aerosols), some elements do approach their UCC ratio after 1 month, suggesting that with sufficient acidification time they may be used as dust indicators. Figure 3 shows changes in the elemental ratios to $\mathrm{Al}$ through time for each acid treatment for $\mathrm{Cs}, \mathrm{Ba}, \mathrm{La}, \mathrm{Ce}, \mathrm{Pr}$ and $\mathrm{K}$, along with their ratio in the UCC (Wedepohl, 1995). While all these elements approach their UCC ratio to $\mathrm{Al}$ within 1-3 months (suggesting that they are dust-derived), it is clear that during the first month the ratio changes dramatically. Indeed, $\mathrm{Ba} / \mathrm{Al}, \mathrm{La} / \mathrm{Al}, \mathrm{Ce} / \mathrm{Al}$ and $\mathrm{Pr} / \mathrm{Al}$ fall both below and above the UCC ratio during the first week of acidification. Differences in the ratios among the three acid treatments are most apparent within the first month. With time, the ratios become more similar among treatments and closer to the UCC ratio. We found similar results for elemental ratios to $\mathrm{Ce}, \mathrm{Fe}, \mathrm{La}$ and $\mathrm{Mn}$ (not shown). These results suggest that dust flux estimates derived using elemental concentrations and crustal ratios will depend on the duration of acidification prior to analysis, and may vary depending on the relative solubility of different minerals.

In order to see how incongruent element leaching might affect interpretations about possible anthropogenic pollution sources, we calculated crustal enrichment factors of $\mathrm{Cs}, \mathrm{Pb}$, As, Cr, $\mathrm{Zn}$ and $\mathrm{U}$ using $\mathrm{Al}$ as a reference element, and found that they all decreased with acidification time, by a factor of $\sim 1.3(\mathrm{~Pb})$ to a factor of $\sim 8$ (Cs) (Fig. 4). In addition, the enrichment factors of $\mathrm{Pb}, \mathrm{As}, \mathrm{Cr}, \mathrm{Zn}$ and $\mathrm{U}$ showed increases within the first month, likely as a result of higher solubility relative to $\mathrm{Al}$. As $\mathrm{Al}$ continued to leach into solution, these enrichment factors all decreased to their final values, as measured at 3 months.

The differences in enrichment factors that we observed with acidification time can be compared with those measured during both preindustrial times and recent decades. We find that the observed change in $\mathrm{EF}_{\mathrm{C}}(\mathrm{As})$, a factor of $\sim 2.6$, is the same as that observed on glacial/interglacial timescales in the European Project for Ice Coring in Antarctica (EPICA) Dome C ice core. This was interpreted to suggest additional non-dust sources, or a possible shift in dust source area or transport parameters (Gabrielli and others, 2005). In contrast, $\mathrm{EF}_{\mathrm{C}}(\mathrm{Pb})$ measured in the Mount Logan ice core, Canada, is a factor of $\sim 15$ above natural background (Osterberg and others, 2008), while we observed changes in $\mathrm{EF}_{\mathrm{C}}(\mathrm{Pb})$ of a factor of $\sim 1.4$. Thus, while our results suggest that enrichment factors calculated within the first month of dissolution are likely to be erroneously high, they would likely not be of the same order as those resulting from anthropogenic pollution. 

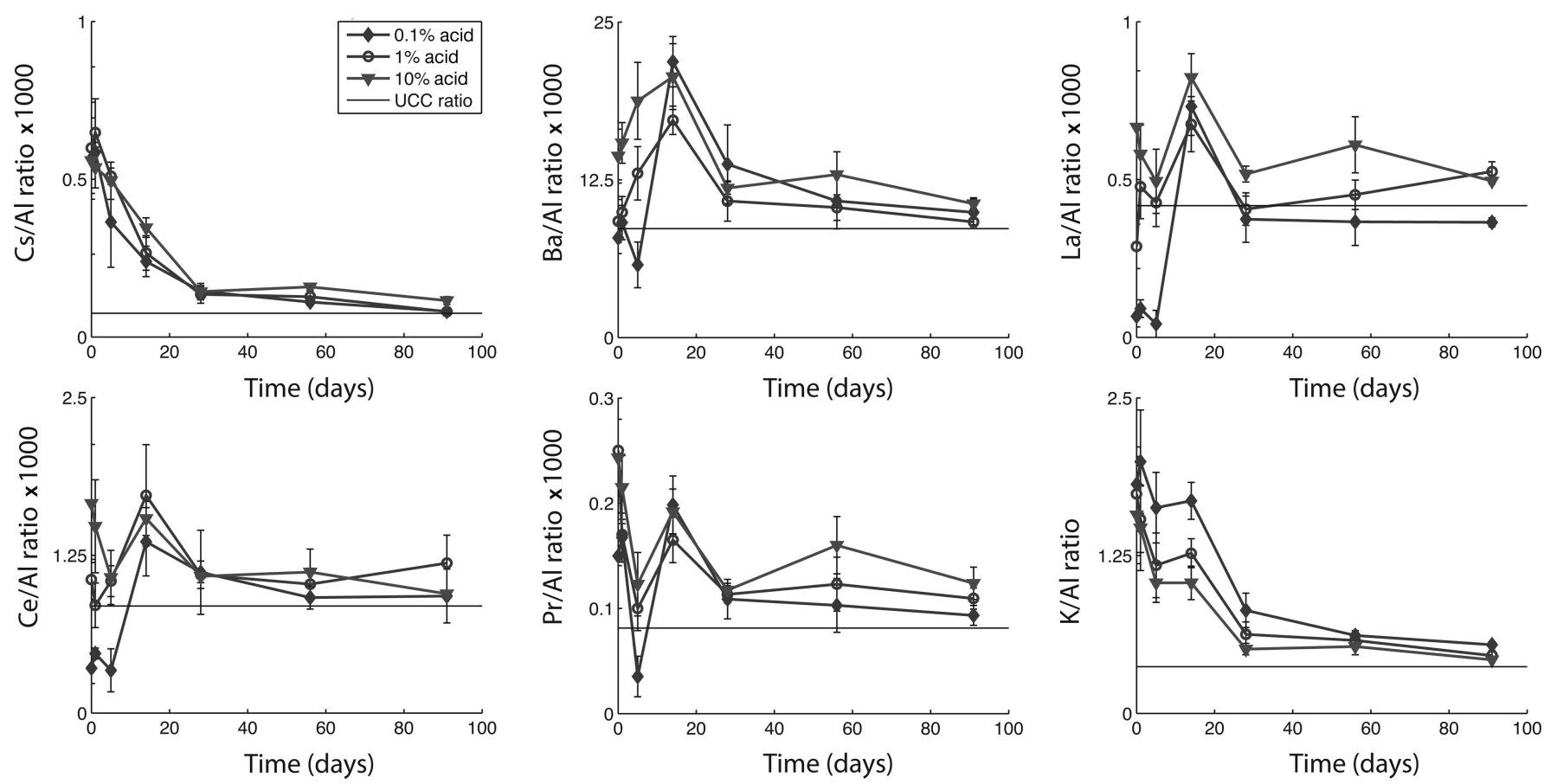

Fig. 3. Ratios of selected elements to AI with acidification time for each acid treatment measured in snow-pit samples from Antarctica. UCC ratios from Wedepohl (1995).

Our results are supported by additional experimental and field measurements. Rhodes and others (2011) found that different rates of element dissolution from crushed rock standards led to very different ratios relative to the UCC ratio through time. They calculated crustal enrichment factors for a hypothetical dust created from four rock standards and leached at $1 \%$ nitric acid for 1 week, and found that $\mathrm{EF}_{\mathrm{C}}(\mathrm{U})$ decreased by a factor of $\sim 2$, using $\mathrm{Al}$ as a reference element (Rhodes and others, 2011). This is comparable with the change in $\mathrm{EF}_{\mathrm{C}}(\mathrm{U})$ that we observed over 3 months. Grotti and others (2011) determined that, compared with a full acid digestion, $<20 \%$ of Fe and $\mathrm{Al}$ contained in Antarctic dust dissolved in a $0.5 \%$ nitric acid treatment. They cautioned against the calculation of crustal enrichment factors using these elements, unless fully digested.

One approach to minimize possible enrichment factor variation due to incongruent dissolution of trace elements is to use multiple reference elements (Osterberg and others, 2008). Given our results that lithogenic elemental ratios approached unity with the UCC ratio and that calculated enrichment factors of trace metals remained relatively constant after 1 month, we suggest that samples to be used
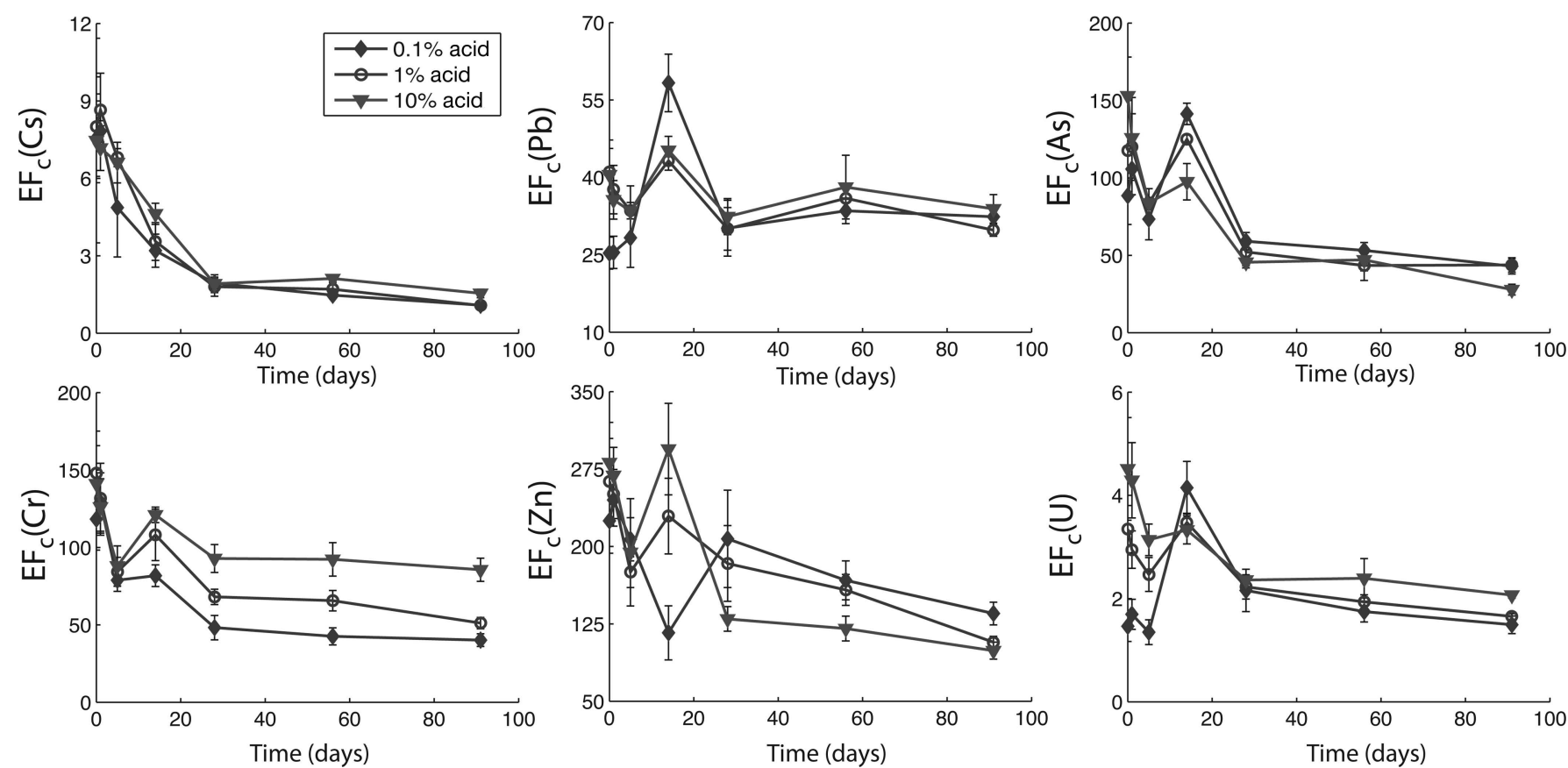

Fig. 4. Calculated crustal enrichment factors of selected elements in Antarctic snow-pit samples, using $\mathrm{Al}$ as a reference element, for each acid treatment. 


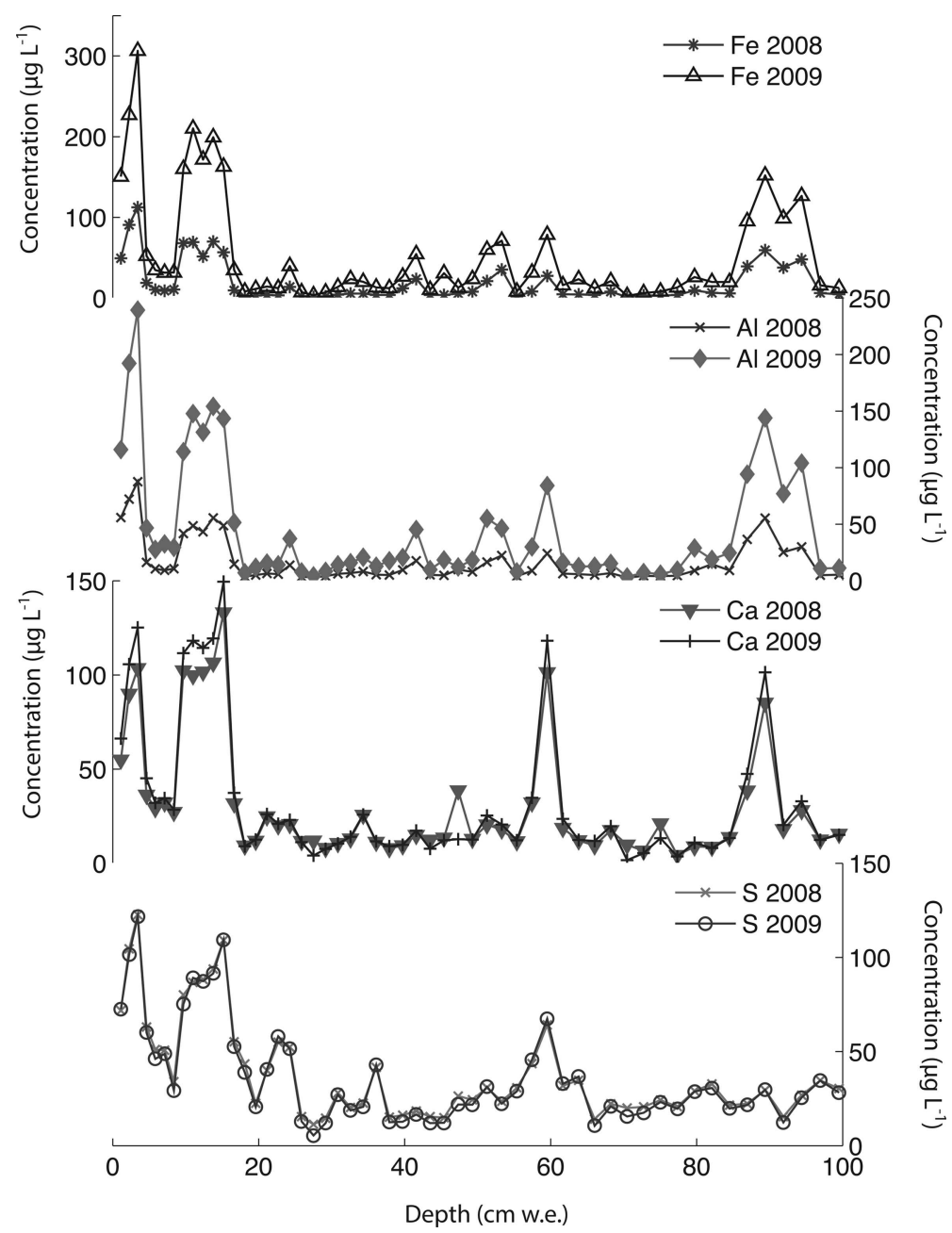

Fig. 5. Concentrations of $\mathrm{S}, \mathrm{Ca}, \mathrm{Al}$ and Fe in Denali snow-pit samples analyzed 383 days apart in 2008 and 2009.

for the calculation of enrichment factors are allowed to sit acidified at room temperature for at least 1 month prior to analysis. However, it must be kept in mind that incomplete dissolution of minerals will likely lead to some degree of overestimation of enrichment due to incongruent leaching; therefore, complete digestion using HF is the best approach when the intent is to calculate crustal enrichment.

\section{Concentration dependence of measured elemental concentration increase}

The Denali snow-pit data allow us to observe concentration changes over an extended time period (383 days) and to evaluate the effect of initial elemental concentration on the observed concentration increase during this time interval. We focus on four elements with different solubilities: $\mathrm{S}, \mathrm{Ca}$, $\mathrm{Al}$ and Fe. Al samples were treated with $1 \%(\mathrm{v} / \mathrm{v})$ nitric acid. Figure 5 shows the measured concentrations of these four elements with depth, for both analysis times. The $\mathrm{S}$ curves are indistinguishable, while the Ca curves are very similar, but with some noticeable increases in concentration at the peak concentrations (e.g. at 3.4, 9.6-15.0, 59.5 and $89.4 \mathrm{~cm}$ depth). The $\mathrm{Al}$ and Fe curves show enhanced concentrations for nearly all values with time, and larger concentration changes within the peaks (as with $\mathrm{Ca}$ ). Repeat measurements of instrumental check standards demonstrate the reproducibility of these data (Table 3). Figure 6 shows the concentration difference between 2009 and 2008 relative to the initial (2008) concentration. The $\mathrm{S}$ data remain around 0 and
Table 3. Concentrations $\left(\mu \mathrm{g} \mathrm{L}^{-1}\right)$ of internal check standard run with the Denali snow-pit samples in 2008 and 2009

\begin{tabular}{|c|c|c|c|c|}
\hline & ${ }^{32} \mathrm{~S}$ & ${ }^{44} \mathrm{Ca}$ & ${ }^{27} \mathrm{Al}$ & ${ }^{56} \mathrm{Fe}$ \\
\hline Check standard value & 50 & 50 & 1 & 1 \\
\hline \multicolumn{5}{|c|}{ Measured concentrations (2008) } \\
\hline Analysis 1 & 47.32 & 51.81 & 1.05 & 1.05 \\
\hline Analysis 2 & 51.85 & 50.62 & 1.03 & 1.09 \\
\hline Analysis 3 & 50.35 & 49.43 & 1.05 & 1.08 \\
\hline Analysis 4 & 49.30 & 48.99 & 1.01 & 0.997 \\
\hline Analysis 5 & 48.53 & 49.06 & 0.974 & 1.04 \\
\hline Analysis 6 & 47.87 & 51.76 & 1.06 & 1.06 \\
\hline 2008 mean & 49.20 & 50.28 & 1.03 & 1.05 \\
\hline 2008 SD & 1.68 & 1.31 & 0.03 & 0.03 \\
\hline \multicolumn{5}{|c|}{ Measured concentrations (2009) } \\
\hline Analysis 1 & 51.04 & 49.26 & 1.04 & 1.04 \\
\hline Analysis 2 & 50.01 & 52.08 & 1.02 & 1.02 \\
\hline Analysis 3 & 51.25 & 50.25 & 1.01 & 1.04 \\
\hline Analysis 4 & 48.84 & 52.33 & 1.01 & 1.00 \\
\hline Analysis 5 & 48.30 & 49.71 & 1.03 & 0.998 \\
\hline Analysis 6 & 51.78 & 50.67 & 1.03 & 0.989 \\
\hline 2009 mean & 50.20 & 50.72 & 1.02 & 1.01 \\
\hline 2009 SD & 1.40 & 1.25 & 0.01 & 0.02 \\
\hline
\end{tabular}




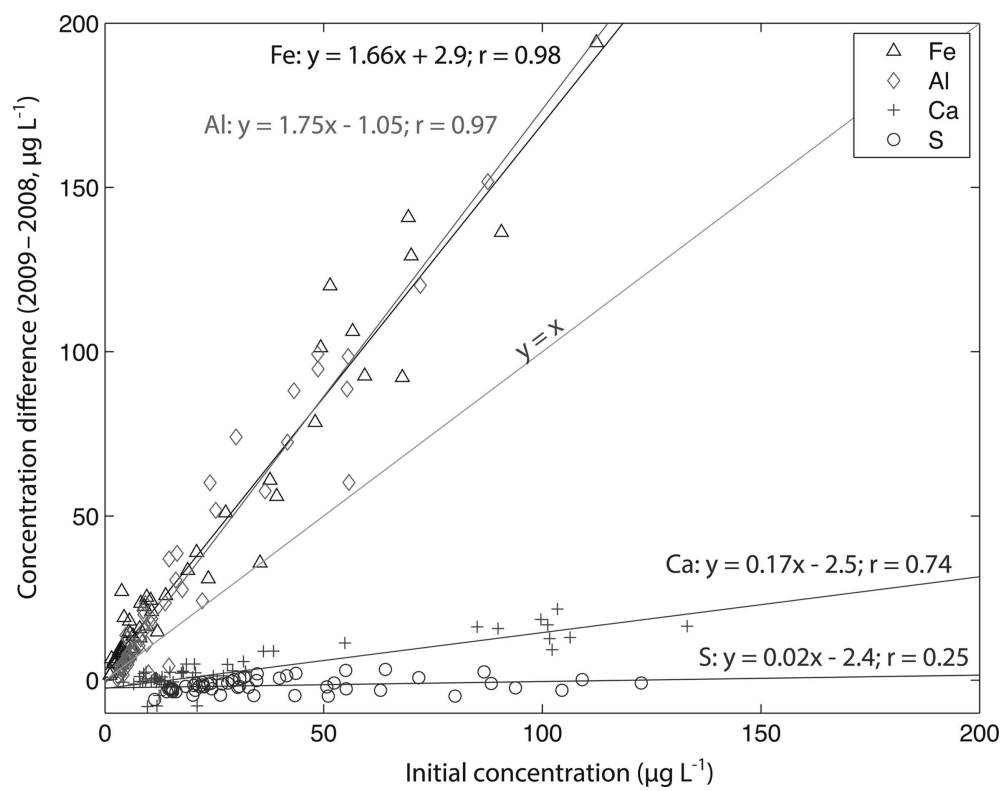

Fig. 6. Change in concentration over 383 days of acidification (2009-2008) vs initial concentration (2008) for S, Ca, Al and Fe measured in a Denali snow pit. Linear regressions are given for each element, and the $y=x$ line is plotted for reference.

show no relationship with initial concentration (linear regression slope $=0.02 ; r=0.25)$. The Ca data show a weak linear relationship between the change in concentration and the initial concentration (linear regression slope $=0.17$; $r=0.74)$. In contrast, the Fe and Al data show strong positive linear relationships between measured concentration difference and initial concentration (Fe linear regression slope $=$ 1.66; $r=0.98 ; \mathrm{Al}$ linear regression slope $=1.75 ; r=0.97$ ). While $\mathrm{Ca}$, Fe and $\mathrm{Al}$ all exhibit a linear relationship between initial concentration and concentration change with time, it is clear that the concentration dependence is much greater for $\mathrm{Fe}$ and $\mathrm{Al}$ than for $\mathrm{Ca}$, suggesting that these elements are being leached from relatively refractory mineral phases. Rhodes and others (2011) used three different concentrations of the W-2 rock standard to look at how leachate concentration related to dust concentration. They found strong linear correlations $(r=0.98-1.00)$ between dust concentration and leachate concentration after 12 hours for $\mathrm{Sr}$ and $\mathrm{Ce}$, in agreement with our results.

\section{Potential implications for snow and ice-core data interpretation}

The finding that analytical methods affect measured traceelement concentrations is not unique. It has been well documented in the oceanographic community, as marine chemists have sought to make clean reproducible measurements of Fe and other trace elements in the upper ocean (Bruland and others, 1979; Achterberg and others, 2001; Bowie and others, 2010) and in dust aerosols (Sholkovitz and others, 2012). However, a quantitative understanding of how methods affect measured chemical concentrations in ice cores is just beginning to emerge (Knüsel and others, 2003; Ruth and others, 2008; Rhodes and others, 2011). Because of the significant differences we observed between measured elemental concentrations at different acid strengths and times, we emphasize that it is essential to treat all samples within individual studies in an identical manner. Moreover, given the variety of methods currently employed in ice-core studies, it is unlikely that two laboratories measuring trace elements in the same samples would achieve the same concentrations, unless they used identical methods.

To estimate the differences between continuous and discrete approaches to ICP-MS analysis of snow and ice-core samples, we use our $20 \mathrm{~min}$ acidification data as a proxy for continuous-injection ICP-MS and compare with our 1 month data $(1 \%(\mathrm{v} / \mathrm{v})$ nitric acid treatments for both cases). We find that $\mathrm{Al}$ increases from $0.534 \pm 0.096$ to $1.74 \pm 0.226 \mu \mathrm{g} \mathrm{L}^{-1}$, an increase of $232 \%$, and Fe increases from $0.402 \pm 0.040$ to $1.45 \pm 0.187 \mu \mathrm{g} \mathrm{L}^{-1}$, an increase of $260 \%$. Pb increases from $4.481 \pm 0.450$ to $11.505 \pm$ $1.025 \mathrm{ng} \mathrm{L}^{-1}$, an increase of $157 \%$, while $\mathrm{EF}_{\mathrm{C}}(\mathrm{Pb})$ decreases by a factor of 1.4 , from $41.1 \pm 6.1$ to $29.8 \pm 1.2$. Similarly, As increases from $1.569 \pm 0.234$ to $2.481 \pm 0.335 \mathrm{ng} \mathrm{L}^{-1}$, an increase of $158 \%$, while $\mathrm{EF}_{\mathrm{c}}$ (As) decreases by a factor of 2.6 , from $117.7 \pm 10.0$ to $43.8 \pm 4.7$. Thus, both elemental concentrations and calculated crustal enrichment factors show significant differences between these two methodological approaches.

Based on these results, we suggest that trends and general patterns (i.e. locations of peaks and troughs in a time-series record) should be consistent among different studies, while absolute concentrations and peak-to-trough amplitudes are likely to differ significantly depending on the acidification method used. Samples to be used for calculation of atmospheric fluxes and crustal enrichment factors must be acidified for at least 1 month prior to analysis to prevent potentially erroneous interpretations of trace-element data, and researchers should bear in mind that incomplete and incongruent leaching is likely to produce overestimates of crustal enrichment. Complete digestion using HF offers the best way to quantify deposition of the full range of trace elements (Correia and others, 2003; Grotti and others, 2011). Incorporating HF digestion even at low temporal resolution in ice-core studies would allow for the quantification of recovery rates, which will be a useful way to compare results obtained from different laboratories. More importantly, quantification of recovery rates would provide some level of standardization among studies conducted in different geographic locations, allowing for more accurate 
interpretations of spatial and temporal variability in traceelement deposition. Given the range of evidence presented here, we suggest that continuous-injection ICP-MS is not an appropriate tool for the quantitative analysis of $\mathrm{Al}, \mathrm{Ba}, \mathrm{Cd}$, $\mathrm{Ce}, \mathrm{Co}, \mathrm{Cr}, \mathrm{Cu}, \mathrm{Fe}, \mathrm{La}, \mathrm{Li}, \mathrm{Mg}, \mathrm{Mn}, \mathrm{Pb}, \mathrm{Pr}, \mathrm{Sr}, \mathrm{Ti}, \mathrm{U}, \mathrm{V}$ or $\mathrm{Zn}$ in ice-core samples. Further, we believe there is a pressing need for a laboratory intercomparison study within the icecore trace-element community.

Our results also have implications for the use of traceelement concentrations as proxies for past climate variability. Proxy development relies on finding meaningful, statistically significant relationships between trace-element concentration records and physical components of the climate system, such as zonal wind strength or sea-ice cover (Mayewski and others, 1994; Kreutz and others, 2000; Goodwin and others, 2004; Yan and others, 2005; Dixon and others, 2012). Relationships are established using observational or climate reanalysis data in the modern era, and interpretations are extended into the past using the ice-core proxy data. Because the commonly used Pearson's linear correlation coefficient depends on actual values (rather than ranked values), our data suggest that the strength of correlation will depend on the relative concentrations of trace elements. Thus, different acidification methods could lead to potentially different socalled 'calibrations' of ice-core data, and therefore different interpretations about past climate variability, particularly in terms of the magnitude of events.

\section{CONCLUSIONS}

We conducted a 3 month experiment to test the effects of acid strength and acidification time on measured traceelement concentrations and calculated crustal enrichment factors in snow samples from West Antarctica. In addition, we used snow-pit samples from Alaska to evaluate the concentration dependence of measured increases in lithogenic element concentrations through time. Our analyses build on previous work (Knüsel and others, 2003; Grotti and others, 2011; Rhodes and others, 2011) by providing clear evidence that trace-element relative concentrations in environmental samples depend on both acid strength and acidification time. Our results suggest the following conclusions:

1. Acid strength and acidification time significantly increase measured trace-element concentrations leached from impurities in snow samples collected from remote locations. Ice-core trace-element studies should allow at least 1 month for dissolution of particulate material in order to achieve a representative acid-leachable fraction. All studies should quantify the recovery rates achieved by their analytical methods using HF digestion.

2. Incongruent dissolution of elements leads to widely varying elemental ratios relative to their UCC ratios through time. Although we observed that many elements approached their crustal ratios after 1 month of acidification, we caution that complete congruent element dissolution can be achieved only through a full acid digestion. Therefore, crustal enrichment factors calculated for samples that have not been digested should be interpreted with this caveat in mind.

3. Lithogenic element dissolution is linearly dependent on dust concentration, though the slope of this relationship is element-specific and may change with dust lithology. Because relative trace-element concentrations depend on the acidification method used, trace-element proxies of past climate variability may not accurately represent the magnitude of past variability in the climate system.

4. An interlaboratory comparison study is needed within the ice-core trace-element community.

\section{ACKNOWLEDGEMENTS}

This work was supported by US National Science Foundation grants ANT-0636740, AGS-1203838 and ARC-0713974 and by the University of Maine Dissertation Research Fellowship to B.G.K. We thank the WAIS Divide Science Coordination Office, Ice Drilling Design and Operations Group, the National Ice Core Laboratory, Raytheon Polar Services Company and the 109th New York Air National Guard for field support in Antarctica. We also thank Timothy Bartholomaus, Thomas Bauska, Seth Campbell, John Fegyveresi, Shelly Griffin, Jonathan Hayden, Logan Mitchell, Anaïs Orsi, Mike Waskiewicz and Gifford Wong for field and laboratory assistance. We thank Nelia Dunbar, Stephen Norton, Rachael Rhodes and an anonymous reviewer for providing helpful comments which improved the manuscript.

\section{REFERENCES}

Achterberg EP, Holland TW, Bowie AR, Mantoura RFC and Worsfold PJ (2001) Determination of iron in seawater. Anal. Chim. Acta, 442(1), 1-14 (doi: 10.1016/S0003-2670(01)01091-1)

Bory A and 6 others (2010) Multiple sources supply eolian mineral dust to the Atlantic sector of coastal Antarctica: evidence from recent snow layers at the top of Berkner Island ice sheet. Earth Planet. Sci. Lett., 291(1-4), 138-148 (doi: 10.1016/ j.epsl.2010.01.006)

Bowie AR, Townsend AT, Lannuzel D, Remenyi TA and Van der Merwe P (2010) Modern sampling and analytical methods for the determination of trace elements in marine particulate material using magnetic sector inductively coupled plasmamass spectrometry. Anal. Chim. Acta, 676(1-2), 15-27 (doi: 10.1016/j.aca.2010.07.037)

Bruland KW, Franks RP, Knauer GA and Martin JH (1979) Sampling and analytical methods for the determination of copper, cadmium, zinc, and nickel at the nanogram per liter level in sea water. Anal. Chim. Acta, 105(1), 233-245 (doi: 10.1016/ S0003-2670(01)83754-5)

Campbell S and 7 others (2012) Melt regimes, stratigraphy, flow dynamics and glaciochemistry of three glaciers in the Alaska Range. J. Glaciol., 58(207), 99-109 (doi: 10.3189/ 2012JoG10J238)

Correia A and 6 others (2003) Trace elements in South America aerosol during 20th century inferred from a Nevado Illimani ice core, Eastern Bolivian Andes (6350 m a.s.I.). Atmos. Chem. Phys. Discuss., 3(3), 2143-2177 (doi: 10.5194/acpd-3-2143-2003)

Cwiertny DM, Young MA and Grassian VH (2008) Chemistry and photochemistry of mineral dust aerosol. Annu. Rev. Phys. Chem., 59, 27-51 (doi: 10.1146/annurev.physchem.59.032607.093630)

Dixon DA and 6 others (2012) An ice-core proxy for northerly air mass incursions into West Antarctica. Int. J. Climatol., 32(10), 1455-1465 (doi: 10.1002/joc.2371)

Dixon DA and 6 others (2013) Variations in snow and firn chemistry along US ITASE traverses and the effect of surface glazing. Cryosphere, 7(2), 515-535 (doi: 10.5194/tc-7-515-2013)

Edwards R, Sedwick P, Morgan V and Boutron C (2006) Iron in ice cores from Law Dome: a record of atmospheric iron deposition for maritime East Antarctica during the Holocene and Last 
Glacial Maximum. Geochem. Geophys. Geosyst., 7(Q12), Q12Q01 (doi: 10.1029/2006GC001307)

Fischer $\mathrm{H}$, Siggaard-Andersen $\mathrm{M}-\mathrm{L}$, Ruth $\mathrm{U}$, Röthlisberger $\mathrm{R}$ and Wolff E (2007) Glacial/interglacial changes in mineral dust and sea-salt records in polar ice cores: sources, transport, and deposition. Rev. Geophys., 45(RG10), RG1002 (doi: 10.1029/ 2005RG000192)

Gabrielli P and 9 others (2005) Variations in atmospheric trace elements in Dome C (East Antarctica) ice over the last two climatic cycles. Atmos. Environ., 39(34), 6420-6429 (doi: 10.1016/j.atmosenv.2005.07.025)

Gabrielli P and 11 others (2010) A major glacial-interglacial change in aeolian dust composition inferred from Rare Earth Elements in Antarctic ice. Quat. Sci. Rev., 29(1-2), 265-273 (doi: 10.1016/j.quascirev.2009.09.002)

Gaspari V and 9 others (2006) Atmospheric iron fluxes over the last deglaciation: climatic implications. Geophys. Res. Lett., 33(3), L03704 (doi: 10.1029/2005GL024352)

Goodwin ID, Van Ommen TD, Curran MAJ and Mayewski PA (2004) Mid-latitude winter climate variability in the south Indian and southwest Pacific regions since 1300 AD. Climate Dyn., 22(8), 783-794 (doi: 10.1007/s00382-004-0403-3)

Gross BH and 6 others (2012) Constraining recent lead pollution sources in the North Pacific using ice-core stable lead isotopes. J. Geophys. Res., 117(D16), D16307 (doi: 10.1029/ 2011JD017270)

Grotti M, Soggia F, Ardini F and Magi E (2011) Major and trace element partitioning between dissolved and particulate phases in Antarctic surface snow. J. Environ. Monitor., 13(9), 2511-2520 (doi: 10.1039/C1EM10215J)

Hong S and 9 others (2004) Atmospheric heavy metals in tropical South America during the past 22,000 years recorded in a high altitude ice core from Sajama, Bolivia. J. Environ. Monitor., 6(4), 322-326 (doi: 10.1039/B314251E)

Knüsel S, Piguet DE, Schwikowski M and Gäggeler HW (2003) Accuracy of continuous ice-core trace-element analysis by inductively coupled plasma sector field mass spectrometry. Environ. Sci. Technol., 37(10), 2267-2273 (doi: 10.1021/ es026452o)

Krachler M, Zheng J, Fisher D and Shotyk W (2005) Analytical procedures for improved trace element detection limits in polar ice from Arctic Canada using ICP-SMS. Anal. Chim. Acta, 530(2), 291-298 (doi: 10.1016/j.aca.2004.09.024)

Krachler M, Zheng J, Fisher D and Shotyk W (2008) Atmospheric inputs of $\mathrm{Ag}$ and $\mathrm{Tl}$ to the Arctic: comparison of a high resolution snow pit (AD 1994-2004) with a firn (AD 1860-1996) and an ice core (previous 16,000 yr). Sci. Total Environ., 399(1-3), 78-89 (doi: 10.1016/j.scitotenv.2008.03.006)

Kreutz KJ and Sholkovitz ER (2000) Major element, rare earth element, and sulfur isotopic composition of a high-elevation ice core: sources and transport of mineral dust in central Asia. Geochem. Geophys. Geosyst., 1(11), 1048 (doi: 10.1029/ 2000GC000082)

Kreutz KJ, Mayewski PA, Pittalwala II, Meeker LD, Twickler MS and Whitlow SI (2000) Sea-level pressure variability in the Amundsen Sea region inferred from a West Antarctic glaciochemical record. J. Geophys. Res., 105(D3), 4047-4059 (doi: 10.1029/ 1999JD901069)
Marino F, Maggi V, Delmonte B, Ghermandi G and Petit JR (2004) Elemental composition ( $\mathrm{Si}, \mathrm{Fe}, \mathrm{Ti}$ ) of atmospheric dust over the last $220 \mathrm{kyr}$ from the EPICA ice core (Dome C, Antarctica). Ann. Glaciol., 39, 110-118 (doi: 10.3189/172756404781813862)

Marteel A and 11 others (2009) Climate-related variations in crustal trace elements in Dome C (East Antarctica) ice during the past 672 kyr. Climatic Change, 92(1-2), 191-211 (doi: 10.1007/ s10584-008-9456-3)

Mayewski PA and 13 others (1994) Changes in atmospheric circulation and ocean ice cover over the North Atlantic during the last 41,000 years. Science, 263(5154), 1747-1751 (doi: 10.1126/science.263.5154.1747)

McConnell JR, Lamorey GW, Lambert SW and Taylor KC (2002) Continuous ice-core chemical analyses using inductively coupled plasma mass spectrometry. Environ. Sci. Technol., 36(1), 7-11 (doi: 10.1021/es011088z)

McConnell JR, Aristarain AJ, Banta JR, Edwards PR and Simões JC (2007) 20th-century doubling in dust archived in an Antarctic Peninsula ice core parallels climate change and desertification in South America. Proc. Natl. Acad. Sci. USA (PNAS), 104(14), 5743-5748 (doi: 10.1073/pnas.0607657104)

Osterberg EC, Handley MJ, Sneed SB, Mayewski PA and Kreutz KJ (2006) Continuous ice-core melter system with discrete sampling for major ion, trace element, and stable isotope analyses. Environ. Sci. Technol., 40(10), 3355-3361 (doi: 10.1021/es052536w)

Osterberg E and 10 others (2008) Ice-core record of rising lead pollution in the North Pacific atmosphere. Geophys. Res. Lett., 35(5), L05810 (doi: 10.1029/2007GL032680)

Reimann C and De Caritat P (2000) Intrinsic flaws of element enrichment factors (EFs) in environmental geochemistry. Environ. Sci. Technol., 34(24), 5084-5091 (doi: 10.1021/es001339o)

Revel-Rolland $M$ and 7 others (2006) Eastern Australia: a possible source of dust in East Antarctica interglacial ice. Earth Planet. Sci. Lett., 249(1-2), 1-13 (doi: 10.1016/j.epsl.2006.06.028)

Rhodes RH, Baker JA, Millet M-A and Bertler NAN (2011) Experimental investigation of the effects of mineral dust on the reproducibility and accuracy of ice-core trace element analyses. Chemical Geol., 286(3-4), 207-221 (doi: 10.1016/j.chemgeo. 2011.05.006)

Ruth $U$ and 15 others (2008) Proxies and measurement techniques for mineral dust in Antarctic ice cores. Environ. Sci. Technol. 42(15), 5675-5681 (doi: 10.1021/es703078z)

Sholkovitz ER, Sedwick PN, Church TM, Baker AR and Powell CF (2012) Fractional solubility of aerosol iron: synthesis of a globalscale data set. Geochim. Cosmochim. Acta, 89, 173-189 (doi: 10.1016/j.gca.2012.04.022)

Vallelonga P, Van de Velde K, Candelone JP, Morgan VI, Boutron CF and Rosman KJR (2002) The lead pollution history of Law Dome, Antarctica, from isotopic measurements on ice cores: $1500 \mathrm{AD}$ to 1989 AD. Earth Planet. Sci. Lett., 204(1-2), 291-306 (doi: 10.1016/S0012-821X(02)00983-4)

Wedepohl KH (1995) The composition of the continental crust. Geochim. Cosmochim. Acta, 59(7), 1217-1232 (doi: 10.1016/ 0016-7037(95)00038-2)

Yan Y, Mayewski PA, Kang S and Meyerson E (2005) An ice-core proxy for Antarctic circumpolar zonal wind intensity. Ann. Glaciol., 41, 121-130 (doi: 10.3189/172756405781813294) 